\title{
Surface Microstructure Formation by ns-, ps-, and fs-Laser Ablation of an Elastomer Composite
}

\author{
Hiroyuki Niino $^{1 *}$, Jürgen Ihlemann ${ }^{2}$, Shigeyuki Ono ${ }^{3}$, and Akira Yabe ${ }^{1}$ \\ ${ }^{1}$ National Institute of Materials and Chemical Research (NIMC), \\ Higashi 1-1, Tsukuba, Ibaraki 305-8565 Japan \\ ${ }^{2}$ Laser-Laboratorium Göttingen e.V., Hans-Adolf-Krebs-Weg 1, D-37077 Göttingen, Germany \\ ${ }^{3}$ NOK Corporations, Tsukuba Technical Laboratory, Wadai 25, Tsukuba, Ibaraki 305-4247 Japan
}

\begin{abstract}
We investigated the laser ablation of an elastomer composite with nanosecond- (ns-), picosecond- (ps-) and femtosecond- (fs-) pulsed UV lasers (ns-laser: $\lambda=248 \mathrm{~nm}, \tau=30 \mathrm{ns;}$ ps-laser: $\lambda=263 \mathrm{~nm}, \tau=8 \mathrm{ps}$; fs-laser: $\lambda=248 \mathrm{~nm}, \tau=500 \mathrm{fs}$ ). Upon laser irradiation, a unique microstructure on the surface of the elastomer composite (acrylate polymer) containing carbon black (particle size: $18-30 \mathrm{~nm}$ ) was observed. The laser-ablated surfaces were analyzed by scanning electron microscopy (SEM) and X-ray photoelectron spectroscopy (XPS). The formation mechanism is discussed in terms of thermal effects induced by the different pulse durations of the lasers.
\end{abstract}

Keywords: UV-laser ablation, surface microstructure, pulse duration effect,

\section{Introduction}

Laser ablation has been used to produce morphological microstructures on the surface of polymer films [1,2], which help to improve adhesive bonding, control surface friction, and align liquid crystals [3]. Recently, we observed the formation of a microstructure containing carbon black on the surface of an elastomer composite (acrylate polymer), upon the irradiation with a nanosecond-pulsed UV laser at a wavelength $(\lambda)$ of $248 \mathrm{~nm}$ with a pulse duration ( $\tau$; Full-width half maximum (FWHM)) of 30 ns. We proposed a mechanism for this microstructure formation based on the aggregation of carbon-rich debris on the top of the microstructures during ablation [4].

In the present study, we investigated the laser ablation of the elastomer composite using nanosecond (ns-), picosecond- (ps-), and femtosecond- (fs-) pulsed UV lasers in order to examine further this formation mechanism. Using ultrashort laser pulses, energy coupling into the sample, thermal energy diffusion, ablation, and removal of material can be different from those induced with ns-excimer laser pulses. In our case, the aggregation of carbon particles is likely to be highly influenced by the duration of the laser pulse. Unique phenomena such as ultra-precision micromachining and multiphoton-absorptioninduced material processing have also been observed in the case of polymers [5-10], metals [11-18], glasses [19,20], ionic crystals [21-23], ceramics [24-26], and semiconductors [27,28].

Moreover, at wavelengths of ca. $250 \mathrm{~nm}$, the carbon particles should be highly absorbent for the photon, whereas absorption by the acrylate polymer should be negligible based on single-photo absorption. Thermal energy diffusion to polymer matrix from carbon particles is also expected to play a key role in the ablation.

\section{Experimental}

Sheet samples of elastomer containing carbon black were prepared by mixing 100 parts of acrylate polymer (1) (Nippon Mektron, PA404K) and 50 parts of carbon black (ISAF grade, particle size: $18-30 \mathrm{~nm}$ ). This mixture was kneaded with rollers and vulcanized after a vulcanizing agent 
and accelerator were added, and was finally compressed into sheet form under $100 \mathrm{kgf} \cdot \mathrm{cm}^{-2}$ through pre-curing at $195 \mathrm{C}(468 \mathrm{~K})$ for $6 \mathrm{~h}$.

$$
-\left(\mathrm{CH}_{2}-\mathrm{CH}-(\mathrm{CO}-\mathrm{O}-\mathrm{R})-\right)_{n}^{-}
$$

$$
\mathrm{R}=\mathrm{C}_{4} \mathrm{H}_{9} \text { or } \mathrm{C}_{2} \mathrm{H}_{4} \mathrm{OCH}_{3}
$$

The sheet samples were irradiated with a ns-laser, a ps-laser, and a fs-laser. The ns-laser irradiation was performed with a conventional $\mathrm{KrF}$ excimer laser (Lambda Physik; EMG201MSC, $\lambda=$ $248 \mathrm{~nm}, \tau=30 \mathrm{~ns}$, intensity $=500 \mathrm{~mJ} \cdot$ puls $^{-1}, 1$ $\mathrm{Hz}$ ) in air. The fourth harmonic wavelength of a Nd:YLF ps-laser (Continuum; $\lambda=263 \mathrm{~nm}, \tau=8 \mathrm{ps,}$ intensity $=1.5 \mathrm{~mJ} \cdot$ pulse $^{-1}, 10 \mathrm{~Hz}$ ) was used for ablation in air. Fs-pulses were produced with a short-pulse $\mathrm{KrF}$ excimer laser system operating at $248 \mathrm{~nm}$ with $\tau=500$ fs $[29,30]$. The fs-laser irradiation was carried out in a vacuum chamber to avoid breakdown of air on the sample. The laser-ablated surfaces of the samples were analyzed by scanning electron microscopy (SEM; Topcon, DS-720). Because of their rather high electrical surface conductivity, these samples were not coated with an additional gold layer before SEM observation. The chemical compositions of the sample surfaces were also analyzed by X-ray photoelectron spectroscopy (XPS, Perkin Elmer,

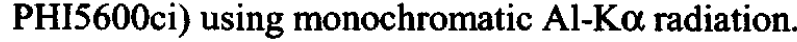

\section{Results and Discussion}

\section{1. ns-laser irradiation}

The ns- KrF excimer laser irradiation $(\lambda=248$ $\mathrm{nm})$ at the fluence $(F)$ of $500 \mathrm{~mJ} \cdot \mathrm{cm}^{-2} \cdot$ pulse $^{-1}$ (peak power $(=\mathrm{F} / \tau): 1.7 \mathrm{MW} \cdot \mathrm{cm}^{-2} \cdot$ pulse $^{-1}$ ) was performed onto the composite surface. A micron-ordered tip-like structure appeared on the surfaces by the laser ablation, and with increases in the number of laser pulses the size of the microstructures became larger. The size of the microstructures having a plateau on the top was gradually changed from ca. $2 \mu \mathrm{m}$ to $30 \mu \mathrm{m}$, upon the ns-laser irradiation with 10,100 , and 500 pulses, as shown in Fig. 1 [4a]. In addition, the density of the microstructure number decreased with increases in the number of laser shots.

XPS observation showed that a strong carbon peak and a small oxygen peak appeared on the surface after the ns-laser ablation, suggesting that the surface of tip-like microstructures consisted of carbon black aggregates [4a].

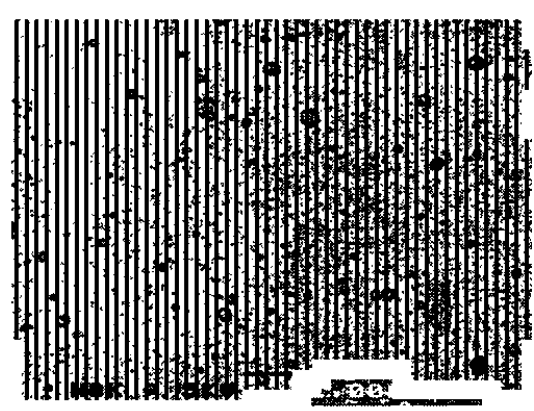

(a)

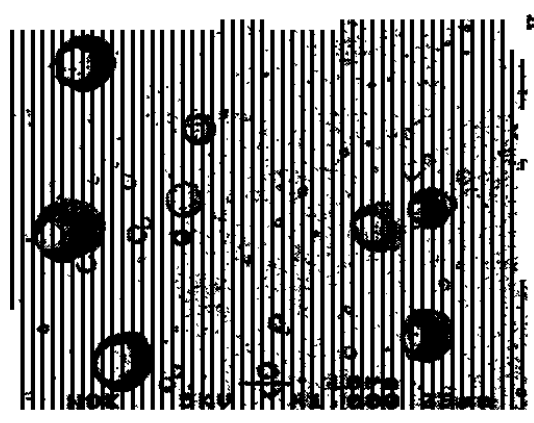

(b)

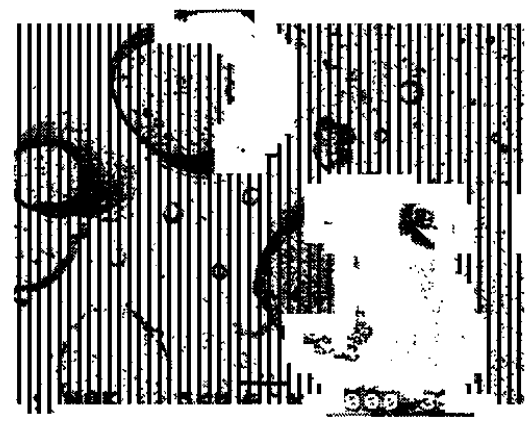

(c)

Fig.1 Top-view SEM micrographs of the surface of the composite after irradiation with the ns-laser with (a) 10 , (b) 100 , (c) 500 pulses at $500 \mathrm{~mJ} \cdot \mathrm{cm}^{-2} \cdot$ pulse $^{-1}$.

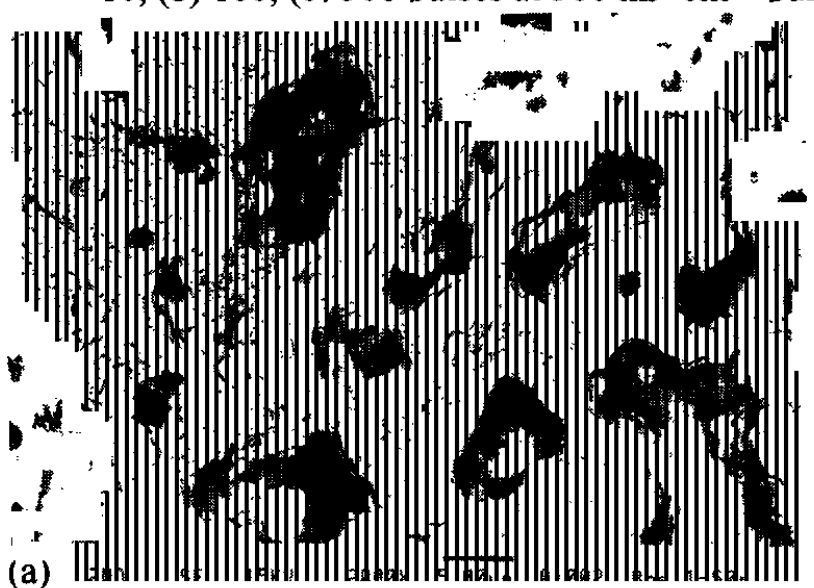

(bar on $\mathrm{SEM}=10 \mu \mathrm{m}$ )

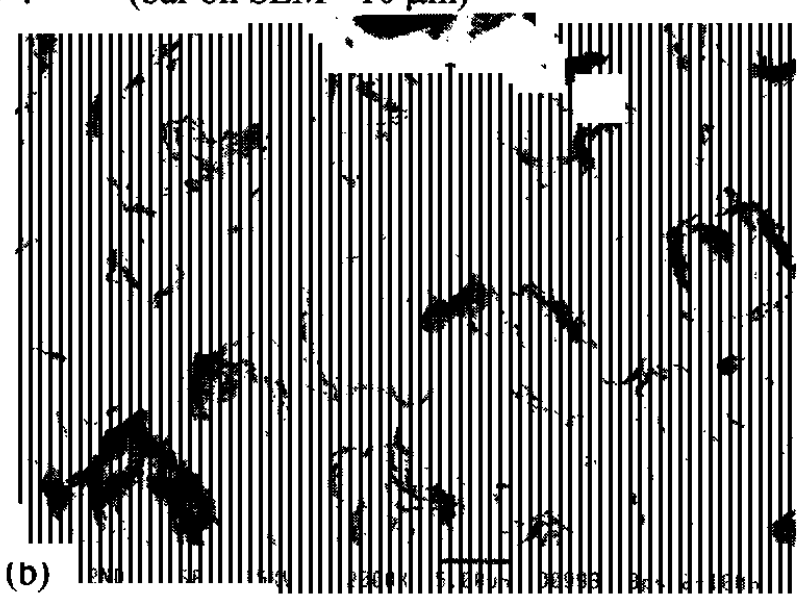

composite after irradiation with the ps-laser with (a) (bar on $\mathrm{SEM}=5 \mu \mathrm{m}$ ) 


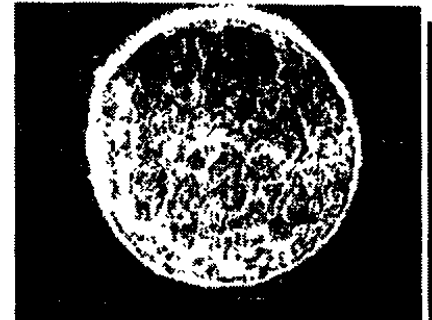

(a) $1.5 \mathrm{~J} \cdot \mathrm{cm}^{-2} \cdot$ pulse $\mathrm{s}^{-1}, 100$ pulses

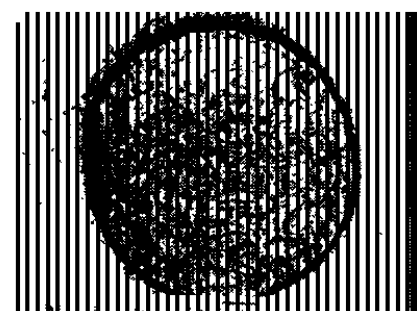

(e) $1.0 \mathrm{~J} \cdot \mathrm{cm}^{-2} \cdot$ pulse $^{-1}, 100$ pulses

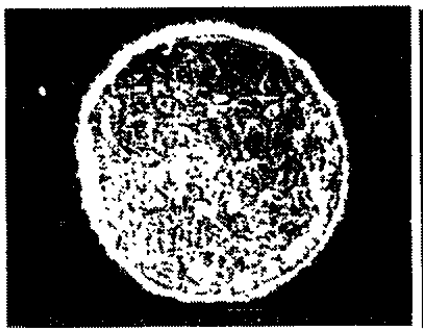

(i) $0.55 \mathrm{~J} \cdot \mathrm{cm}^{-2} \cdot$ pulse ${ }^{-1}, 100$ pulses

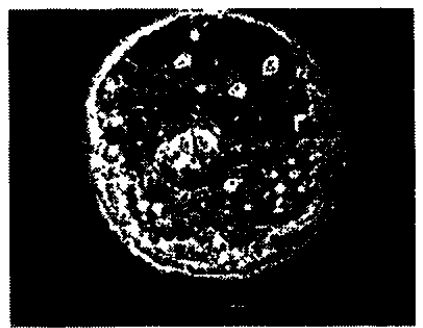

(m) $0.3 \mathrm{~J} \cdot \mathrm{cm}^{-2} \cdot$ pulse $e^{-1}, 100$ pulses (n) $0.3 \mathrm{~J} \cdot \mathrm{cm}^{-2} \cdot$ pulse ${ }^{-1}, 50$ pulses
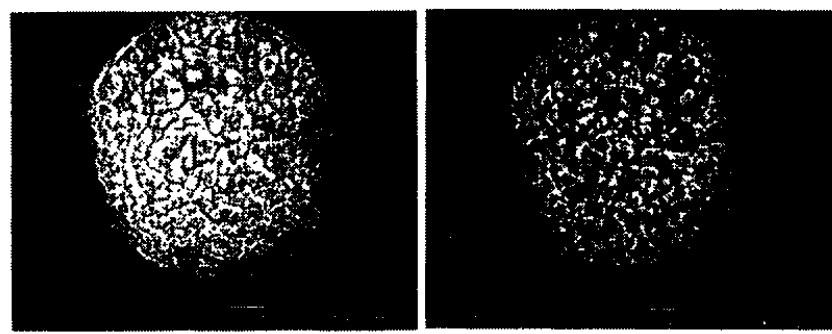

(q) $0.14 \mathrm{~J} \cdot \mathrm{cm}^{-2} \cdot$ pulse ${ }^{-1}, 100$ pulses (r) $0.14 \mathrm{~J} \cdot \mathrm{cm}^{-2} \cdot$ pulse $e^{-1}, 50$ pulses

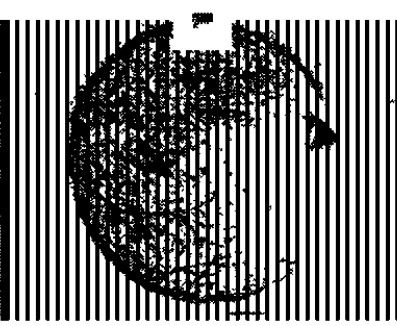

(t) $1.0 \mathrm{~J} \cdot \mathrm{cm}^{-2} \cdot$ pulse ${ }^{-1}, 50$ pulses

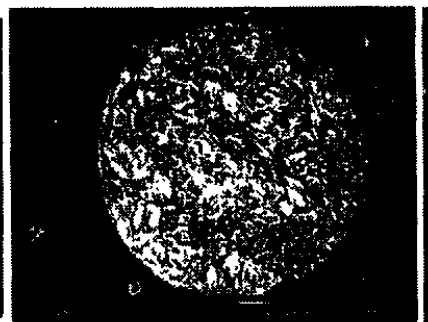

(c) $1.5 \mathrm{~J} \cdot \mathrm{cm}^{-2} \cdot$ pulse ${ }^{-1}, 10$ pulses

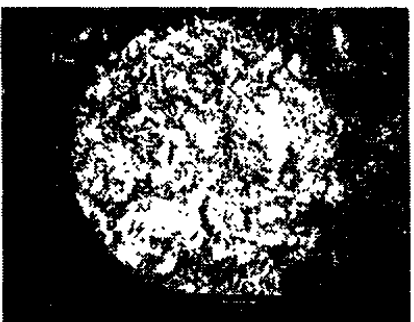

(d) $1.5 \mathrm{~J} \cdot \mathrm{cm}^{-2} \cdot$ pulse ${ }^{-1}, 5$ pulses

(g) $1.0 \mathrm{~J} \cdot \mathrm{cm}^{-2} \cdot$ pulse ${ }^{-1}, 10$ pulses

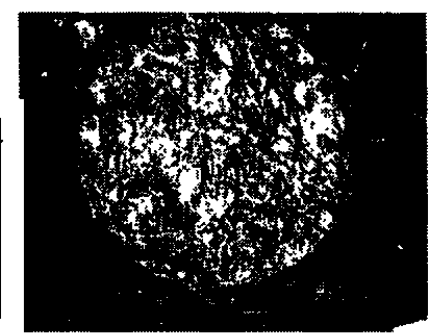

(h) $1.0 \mathrm{~J} \cdot \mathrm{cm}^{-2} \cdot$ pulse $^{-1}, 5$ pulses
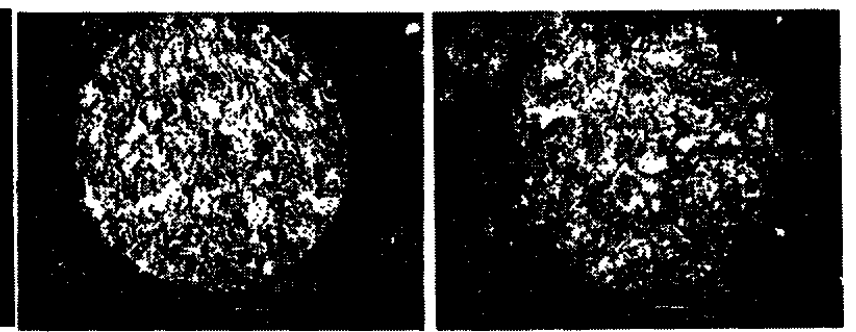

(k) $0.55 \mathrm{~J} \cdot \mathrm{cm}^{-2} \cdot$ pulse ${ }^{-1}, 10$ pulses
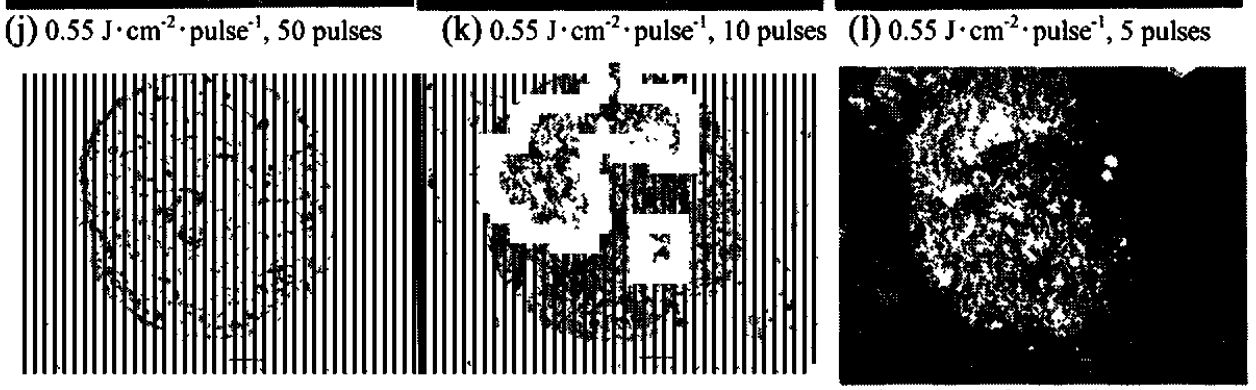

(o) $0.3 \mathrm{~J} \cdot \mathrm{cm}^{-2} \cdot$ pulse ${ }^{-1}, 10$ pulses
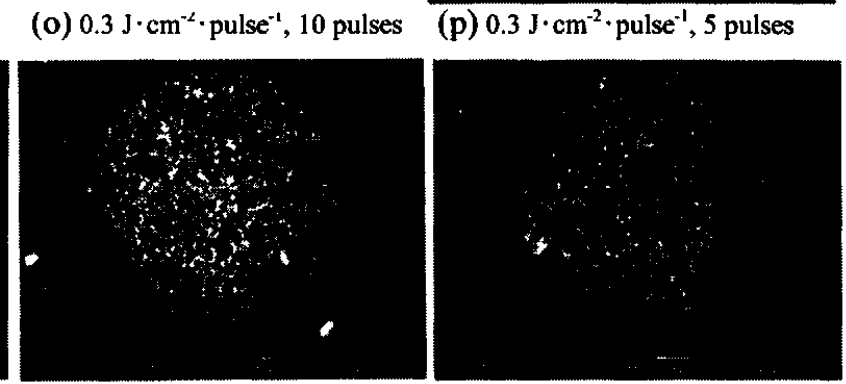

(s) $0.14 \mathrm{~J} \cdot \mathrm{cm}^{-2} \cdot$ pulse ${ }^{-1}, 10$ pulses (t) $0.14 \mathrm{~J} \cdot \mathrm{cm}^{-2} \cdot$ pulse ${ }^{-1}, 5$ pulses

Fig.3 Top-view SEM micrographs of the surface of the composite after irradiation with the fs-laser at

(a-d) $1.5 \mathrm{~J} \cdot \mathrm{cm}^{-2} \cdot$ pulse ${ }^{-1}$ with $100,50,10,5$ pulses (peak power: $3.0 \mathrm{TW} \cdot \mathrm{cm}^{-2} \cdot$ pulse ${ }^{-1}$ ),

(e-h) $1.0 \mathrm{~J} \cdot \mathrm{cm}^{-2} \cdot$ pulse ${ }^{-1}$ with $100,50,10,5$ pulses $\left(2.0 \mathrm{TW} \cdot \mathrm{cm}^{-2} \cdot\right.$ pulse $\left.\mathrm{s}^{-1}\right)$,

(i-1) $0.55 \mathrm{~J} \cdot \mathrm{cm}^{-2} \cdot$ pulse $^{-1}$ with $100,50,10,5$ pulses $\left(1.1 \mathrm{TW} \cdot \mathrm{cm}^{-2} \cdot\right.$ pulse $\left.e^{-1}\right)$,

(m-p) $0.30 \mathrm{~J} \cdot \mathrm{cm}^{-2} \cdot$ pulse $e^{-1}$ with $100,50,10,5$ pulses $\left(0.60 \mathrm{TW} \cdot \mathrm{cm}^{-2} \cdot\right.$ pulse $\left.^{-1}\right)$,

(q-t) $0.14 \mathrm{~J} \cdot \mathrm{cm}^{-2} \cdot$ pulse $^{-1}$ with $100,50,10,5$ pulses $\left(0.28 \mathrm{TW} \cdot \mathrm{cm}^{-2} \cdot\right.$ pulse $\left.{ }^{-1}\right) . \quad$ (bar on $\left.\mathrm{SEM}=37 \mu \mathrm{m}\right)$

\section{2. ps-laser irradiation}

Figure 2 shows SEM pictures of the surface after ps-laser irradiation $(\lambda=263 \mathrm{~nm})$ at a fluence of $500 \mathrm{~mJ} \cdot \mathrm{cm}^{-2} \cdot$ pulse $^{-1}$ (peak power: $62.5 \mathrm{GW}$. $\mathrm{cm}^{-2} \cdot$ pulse $\left.^{-1}\right)$. The size of tip-like microstructures (4-8 $\mu \mathrm{m})$ is smaller than that found in cases of ns-laser irradiation. As the microstructures in ns-laser ablation formed under same conditions in 
terms of laser fluence and shots, the differences between the microstructures must be explained as being the results of differences in pulse duration.

In addition, the ablation induced by ps-laser irradiation showed that the density and size of microstructures did not change significantly with increases in the number of laser shots, whereas those of ns-laser ablated surface strongly depended on the number of laser shots.

\section{3. fs-laser irradiation}

A drastic change on the surface was observed upon fs-laser irradiation. Instead of the tip-like microstructures, a roughness appeared on the surface after fs-laser ablation at fluences of 0.14-1.5 J $\cdot \mathrm{cm}^{-2} \cdot$ pulse $^{-1}$ (peak power: 0.28-3.0 $\mathrm{TW} \cdot \mathrm{cm}^{-2} \cdot$ pulse $\left.^{-1}\right)$, as shown in Fig. 3. This domain structure can be ascribed to the original structure of internal high-order network structure of the sample [31]. In higher fluence regions up to $1.5 \mathrm{~J} \cdot \mathrm{cm}^{-2} \cdot$ pulse $^{-1}$, a similar roughness was produced on the surface. Moreover, there was only a negligible accumulation effect for the number of laser shots. The shape of the microstructure did not change with increases in the number of laser shots. These results indicate that this kind microstructure is due to the negligibly low thermal effects induced by fs-laser irradiation.

\subsection{Mechanism for microstructure formation}

Thermal diffusion length $(L)$ is related to thermal diffusivity $(D)$ and time $(\tau)$; [2]

$$
L \approx 2(D \tau)^{0.5} \text {. }
$$

Table 1 shows the thermal diffusion length for the acrylate polymer and carbon (graphite) at different laser pulse durations, based on eq. (2). If we assume a perfect mixing of the carbon particles (average size: $24 \mathrm{~nm}$ ) within the acrylate polymer in our sample, the average distance between neighboring particles would be approximately 33 $\mathrm{nm}$ in the polymer matrix. Since, upon irradiation with the ns-laser, the diffusion length of the polymer was much larger than the distance between neighboring particles, the polymer matrix would be heated enough to accelerate carbon aggregation during the ns-laser pulse.

However, in the case of a ps-laser, the thermal diffusion length of acrylate polymer is decreased about one order magnitude over the average distance between neighboring carbon particles.
This suggests that the lower thermal diffusion length upon the ps-laser irradiation resulted in a smaller microstructure due to a lower level of carbon aggregation. The ps-laser ablation showed an intermediate stage of microstructure development between ns-laser and fs-laser ablation

It is worth noting that the threshold fluence of the composite sample was ca. $40 \mathrm{~mJ} \cdot \mathrm{cm}^{-2} \cdot$ pulse for ablation with the ps-laser irradiation, whereas the threshold fluence for the graphite was ca. 300 $\mathrm{mJ} \cdot \mathrm{cm}^{-2} \cdot$ pulse $^{-1}$. Since the threshold fluence for conventional polymers having high absorption in the $\mathrm{UV}$ region is $50-30 \mathrm{~mJ} \cdot \mathrm{cm}^{-2} \cdot$ pulse $^{-1}[1,3]$, these results suggest that the carbon particles and aggregates on the surface behaved as a photon absorber decomposing polymer chains through thermal energy transfer.

Table 1. Thermal diffusion lengths $(L)$ of acrylate polymer and carbon at different times $(\tau)$.

\begin{tabular}{ccc}
\hline \multirow{2}{*}{$\tau$} & \multicolumn{2}{c}{$L$} \\
\cline { 2 - 3 } & $\begin{array}{c}\text { acrylate } \\
\text { polymer }\end{array}$ & $\begin{array}{c}\text { carbon } \\
\text { (graphite) }\end{array}$ \\
\hline $30 \mathrm{~ns}$ & $160 \mathrm{~nm}$ & $3500 \mathrm{~nm}$ \\
$8 \mathrm{ps}$ & $2.5 \mathrm{~nm}$ & $56 \mathrm{~nm}$ \\
$500 \mathrm{fs}$ & $0.63 \mathrm{~nm}$ & $14 \mathrm{~nm}$ \\
\hline
\end{tabular}

${ }^{\text {a) }} D$ of acrylate polymer at RT: $0.002 \mathrm{~cm}^{2} \cdot \mathrm{s}^{-1}$

b) $D$ of graphite at RT: $1.0 \mathrm{~cm}^{2} \cdot \mathrm{s}^{-1}$

Table 1 also shows that the fs-regime had the lowest diffusion length in comparison with the other three time regimes. Carbon aggregation on a surface irradiated with a fs-laser would be suppressed when the photon energy is accumulated into the sample. The suppression to form carbon aggregates did not induce the tip-like microstructure on the fs-laser-treated surface.

Table 2. The atomic ratio of carbon $\left(\mathrm{C}_{1 \mathrm{~s}}\right)$ and oxygen $\left(\mathrm{O}_{\mathrm{ss}}\right)$ before and after fs-laser irradiation (Atomic factor: $\mathrm{C}_{\mathrm{ls}}=0.296, \mathrm{O}_{\mathrm{ls}}=0.771$ ).

\begin{tabular}{|c|c|}
\hline Laser irradiation & $\begin{array}{l}\text { Atomic ratio } \\
\left(\mathrm{O}_{1 \mathrm{~s}} / \mathrm{C}_{\mathrm{ls}}\right)\end{array}$ \\
\hline Before irradiation & 0.25 \\
\hline $\begin{array}{c}1.9 \mathrm{~J} \cdot \mathrm{cm}^{-2} \cdot \text { pulse }^{-1} \\
\left(3.8 \mathrm{TW} \cdot \mathrm{cm}^{-2} \cdot \text { pulss }^{-1}\right) \\
\text { with } 9 \text { pulses }\end{array}$ & 0.27 \\
\hline $\begin{array}{c}400 \mathrm{~mJ} \cdot \mathrm{cm}^{-2} \cdot \text { pulse }^{-1} \\
\left(0.8 \mathrm{TW} \cdot \mathrm{cm}^{-2} \cdot \text { pulse }\right. \\
\text { with } 9 \text { pulses }\end{array}$ & 0.28 \\
\hline
\end{tabular}




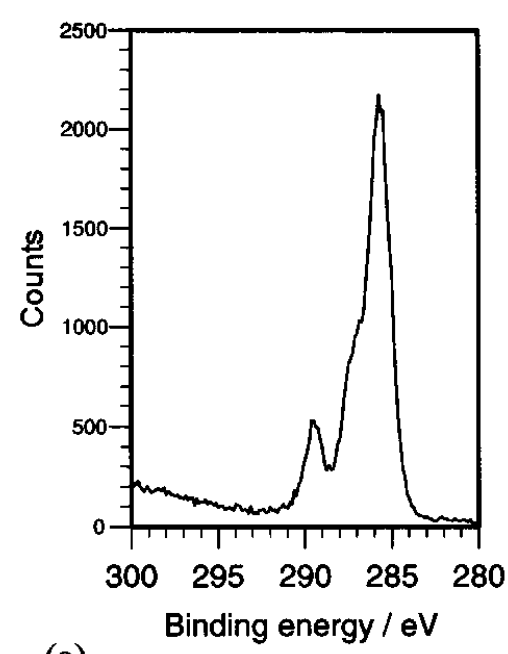

(a)

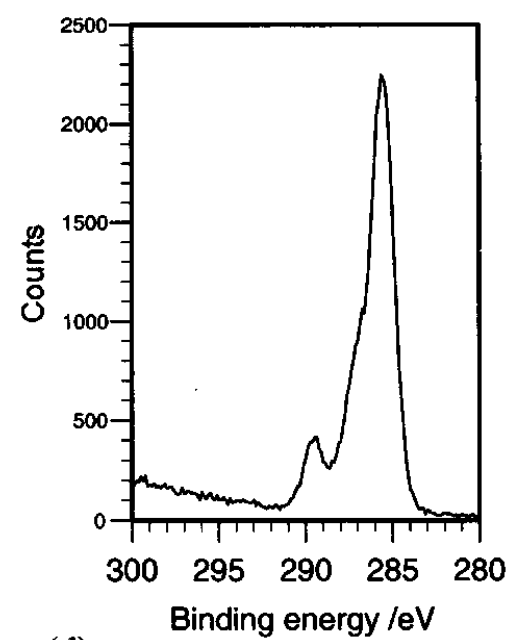

(d)

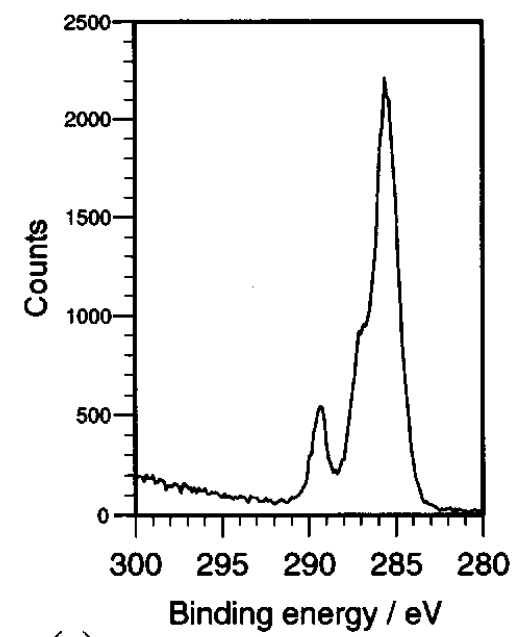

(g) $(\mathrm{h})$

Fig.4: XPS fine spectra (a,d,g: $C_{1 s}$ region),(b,e,h: $O_{1 s}$ region) and $S E M$ pictures $(c, f, i)$ of the surface of the composite; $(a, b, c)$ before laser irradiation, $(d, e, f)$ after irradiation of the fs-laser at $1.9 \mathrm{~J} \cdot \mathrm{cm}^{-2} \cdot \mathrm{pulse}^{-1}$ with 9 pulses, $(\mathrm{g}, \mathrm{h}, \mathrm{i})$ at $400 \mathrm{~mJ} \cdot \mathrm{cm}^{-2} \cdot$ pulse $^{-1}$ with 9 pulses.
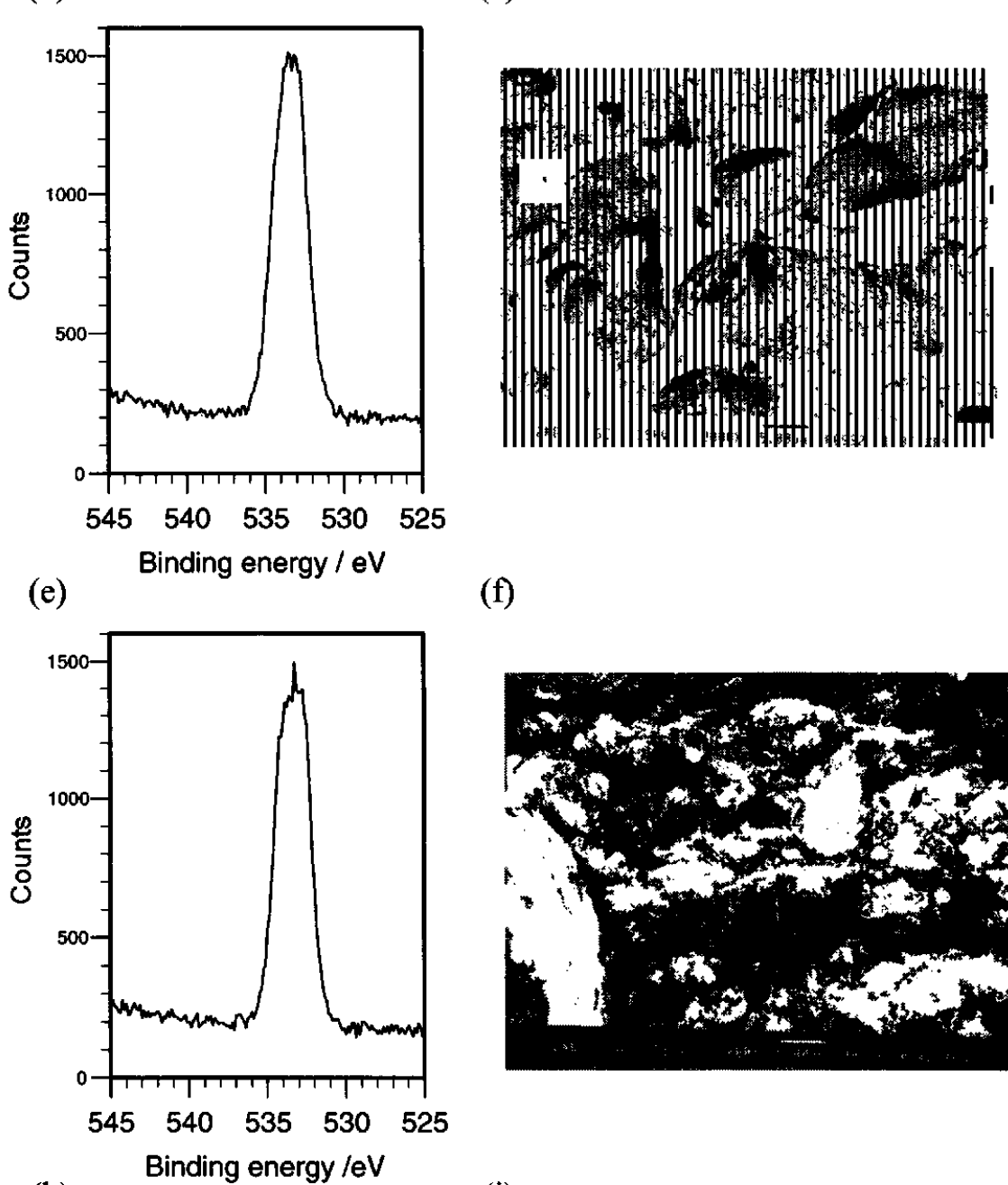

(f)

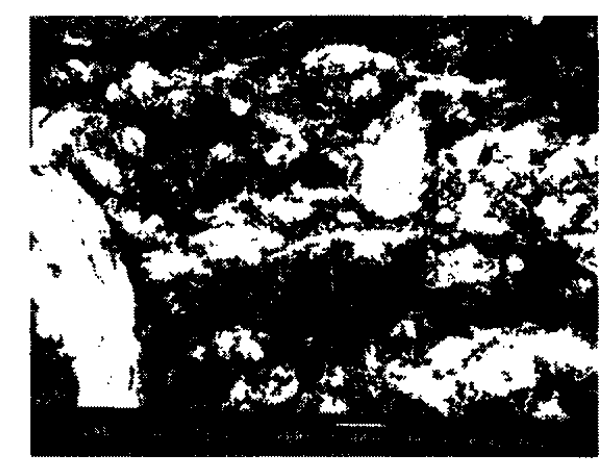

(i)
Moreover, Küper and Stuke reported that polymethylmethacrylate (PMMA), whose singlephoton absorption at $248 \mathrm{~nm}$ is negligible, showed higher absorption induced by $300 \mathrm{fs}$ UV excimer laser irradiation at $248 \mathrm{~nm}$, due mainly to nonlinear absorption enhanced by the ultra-short laser 
irradiation [5]. Upon fs-laser and ps-laser irradiations, the photo-absorption of the polyacrylate matrix in the composite would be increased in comparison with that induced by ns-laser irradiation. Especially, non-thermal effects and the non-linear absorption of the matrix polymer would cause the unique shape of the microstructure formation on the fs-laser ablation.

This assumption is supported by an XPS analysis of the surface. Table 2 indicates that there was no significant difference in the atomic ratio of carbon and oxygen before and after fs-laser irradiation. Figure 3 shows fine XPS spectra of carbon $\left(\mathrm{C}_{1 \mathrm{~s}}\right)$ and oxygen $\left(\mathrm{O}_{1 \mathrm{~s}}\right)$ regions of the sample surface. The $\mathrm{C}_{1 \mathrm{~s}}$ and $\mathrm{O}_{\mathrm{is}}$ spectra indicate negligible change between before and after laser irradiation, suggesting that the fs-laser irradiation did not modify the chemical composition of the sample surface. This means that carbon aggregations on the irradiated area were suppressed under fs-laser ablation. Selection of an appropriate laser-pulse duration can regulate the thermal effects on ablated surfaces of the sample.

\section{Conclusion}

The laser ablation of an elastomer composite was investigated using different time regimes of laser pulse at $30 \mathrm{~ns}, 8 \mathrm{ps}$, and $500 \mathrm{fs}$. Intrinsic laser ablation without thermal effects was demonstrated in an experiment of fs-laser ablation of the composite, where the heat-affected zone on the surface during laser irradiation was negligible. These advantages of fs-lasers are very promising for various applications in precise material processing.

\section{References}

1. R. Srinivasan, B. Braren, Chem. Rev. 89 (1989) 1303.

2. D. Bäuerlre: Laser Processing and Chemistry, 2nd Edn. (Springer, Berlin, Heidelberg 1996) p. 21.

3. H. Niino, A. Yabe, S. Nagano, T. Miki, Appl. Phys. Lett. 54 (1989) 2159; H. Niino, M. Nakano, S. Nagano, A. Yabe, T. Miki, Appl. Phys. Lett. 55 (1989) 510; H. Niino, M. Shimoyama, A. Yabe, Appl. Phys. Lett. 57 (1990) 2368; H. Niino, Y. Kawabata, A. Yabe,
Jpn. J. Appl. Phys. 28 (1989) L2225; H. Niino, Y. Koga, A. Yabe, J. Photochem. Photobiol. A: Chem. 65 (1992) 303.

4. (a) S. Ono, S. Nakaoka, J. Wang, H.Niino, A. Yabe, Jpn. J. Appl. Phys. 36 (1997) L1387; (b) S. Ono, S. Nakaoka, J. Wang, H.Niino, A. Yabe, Appl. Surf. Sci. 127-129 (1998) 821; (c) J.-F. Silvain, H.Niino, S. Ono, S. Nakaoka, A. Yabe, Appl. Surf. Sci. 141 (1999) 25, (d) A. Yabe, H. Niino,, S. Ono, Y.Sato, SPIE Proc., 2992 (1997) 119.

5. S. Küper, M. Stuke, Appl. Phys. B 44 (1987) 199.

6. S. Küper, M. Stuke, Appl. Phys. Lett. 54 (1989) 4.

7. R. Srinivasan, E. Sutcliffe, B. Braren, Appl. Phys. Lett. 51 (1987) 1285.

8. M. Lassithiotaki, A. Athanassiou, D. Anglos, S. Georiou, C. Fotakis, Appl. Phys., A69 (1999) S363; B. Hopp, Z. Toth, K. Gal, A. Mechler, Zs. Bor, S. D. Moustaizis, S. Georgiou, C. Fotakis, Appl. Phys., A69 (1999) S191.

9. K. Hatanaka, T. Itoh, T. Asahi, N. Ichinose, S. Kawanishi, T. Sasuga, H. Fukumura, H. Masuhara, Chem. Phys. Lett., 300 (1999) 727.

10. S. Baudash, J. Bose, W. Kautek, Appl. Phys., A69 (1999) S395

11. B. N. Chichkov, C. Momma, S. Nolte, F. von Alvensleben, A. Tuennermann, Appl. Phys. A63 (1996) 109.

12. A. Semerok, C. Chaleard, V. Detalle, J.-L. Lacour, P. Mauchien, P. Meynadier, C. Nouvellon, B. Salle, P. Palianov, M. Perdrix, G. Petite, Appl. Surf. Sci., 138-139 (1999) 311.

13. J.-H. Klein-Wiele, G. Marowsky, P. Simon, Appl. Phys., A69 (1999) S187; J. Bekesi, R. Vajtai, P. Simon, L. B. Kiss, Appl. Phys., A69 (1999) S385.

14. X. Zhu, A. Yu. Naumov, D. M. Villeneuve, P. B. Corkum, Appl. Phys., A69 (1999) S367.

15. P. S. Banks, M. D. Feit, A. M. Rubenchik, B. C. Stuart, M. D. Perry, Appl. Phys., A69 (1999) S377.

16. B. Salle, O. Gobert, P. Meynadier, M. Perdrix, G. Petite, A. Semerok, Appl. Phys., A69 (1999) S381.

17. B. Rothfeld, A. Kaiser, M. Vicanek, G. Simon, Appl. Phys., A69 (1999) S109.

18. K. Furusawa, K. Takahashi, H. Kumagai, K. Midorikawa, M. Obara, Appl. Phys., A69 (1999) S359.

19. J. Ihlemann, B. Wolff, P. Simon, Appl. Phys. A54 (1992) 363. 
20. M. Lenzner, J. Krüger, S. Sartania, Z. Cheng, Ch. Spielmann, G. Mourou, W. Kautek, F. Krausz, Phys. Rev. Lett., 80 (1998) 4076; P. Rudolph, J. Bonse, J. Krüger, W. Kautek, Appl. Phys., A69 (1999) S763.

21. D. Ashkenasi, H. Varel, A. Rosenfeld, F. Noack, E. E. B. Campbell, Appl. Phys. A63 (1996) 103; A. Rosenfeld, M. Lorenz, R. Stoian, D. Ashkenasi, Appl. Phys., A69 (1999) S373.

22. W. P. Hess, A. G. Joly, K. M. Beck, R. M. Williams, J. T. Dickinson, Appl. Phys., A69 (1999) S389; A. G. Joly, K. M. Beck, W. P. Hess, Appl. Phys., A69 (1999) S153.

23. J. Krüger, W. Kautek, H. Newesely, Appl. Phys., A69 (1999) S403.

24. J. Ihlemann, A. Scholl, H. Schmidt, B. Wolff-Rottke, Appl. Phys. A60 (1995) 411; F Beinhorn, J. Ihlemann, P. Simon, G. Marowsky, B. Maisenholder, J. Edlinger, D. Neuschafer, D.
Anselmetti, Appl. Surf. Sci., 138-139 (1999) 107.

25. J. Bose, M. Geuss, S. Baudash, H. Sturm, W. Kautek, Appl. Phys., A69 (1999) S399.

26. M. Henyk, N. Vogel, D. Wolfframm, A. Tempel, J. Reif, Appl. Phys., A69 (1999) S355.

27. A. Cavalleri, K. Sokolowshi-Tinten, J. Bialkowski, M. Schreiner, D. von der Linde, $J$. Appl. Phys., 85 (1999) 3301.

28. M.Mosbacher, N. Chaoui, J. Siegel, V. Dobler, J. Solis, J. Boneberg, C. N. Afonso, P. Leiderer, Appl. Phys., $\mathrm{A} 69$ (1999) S331.

29. K. Chen, J. Ihlemann, P. Simon, I. Baumann, W. Sohler, Appl. Phys. A65 (1997) 517.

30. S. Szatmári, F. P. Schäfer, Opt. Commun. 68 (1988) 196.

31. S. Ono, M. Ito, H. Tokumitsu, K. Seki, J. Appl. Polym. Sci., 74 (1999) 2529. 